\title{
ANTAGONISMO DE Pseudomonas fluorescens Migula FRENTE A Fusarium oxysporum fsp. pisi Schtdl EN ARVEJA Pisum sativum L.
}

\author{
ANTAGONISM OF Pseudomonas fluorescens Migula \\ FACING Fusarium oxysporum fsp. pisi SchtdI ON PEA \\ Pisum sativum L.
}

\begin{abstract}
Germán Andrés Guerra1', Carlos Arturo Betancourth², Claudia Elizabeth Salazar³
${ }^{1}$ I.A. Egresado Facultad de Ciencias Agrícolas, Universidad de Nariño, Ciudad Universitaria - Torobajo, bloque 2 piso 2, Pasto-Colombia, e-mail: germanandresguerra@gmail.com 2 I.A. M.Sc. Profesor Asociado. Grupo de Investigación Sanidad Vegetal Facultad de Ciencias Agrícolas, Universidad de Nariño, Ciudad Universitaria - Torobajo, bloque 2 piso 2, Pasto-Colombia, e-mail: cbet70@ yahoo.com ${ }^{3}$ I.A. M.Sc. Profesora Asistente. Grupo de Investigación Sanidad Vegetal, Facultad de Ciencias Agrícolas, Universidad de Nariño, Ciudad Universitaria - Torobajo, bloque 2 piso 2, Pasto-Colombia, e-mail: claudiasalazarg@yahoo.com
\end{abstract}

Rev. U.D.C.A Act. E Div. Cient. 14(2): 33 - 42, 2011

\section{RESUMEN}

Uno de los principales problemas fitopatológicos que afecta el cultivo de arveja es el amarillamiento causado por el hongo Fusarium oxysporum, generando pérdidas considerables en las zonas productoras. Este trabajo, se llevó a cabo en el laboratorio e invernadero de la Universidad de Nariño, situado a una altura de $2.486 \mathrm{msnm}$, a una temperatura promedio de $18^{\circ} \mathrm{C}$, con el fin de evaluar el antagonismo de $P$. fluorescens frente a $F$. oxysporum en arveja $\mathrm{L}$. El aislamiento de $F$. oxysporum, se realizó tomando tejidos afectados de raíces y de tallos de plantas de arveja, los cuales, se sembraron, se purificaron y se multiplicaron en PDA; la selección de la cepa, se efectuó con base en la prevalencia en todas las zonas y por la velocidad en su crecimiento, obteniendo la cepa FTR. El aislamiento de $P$. fluorescens, se practicó en raíces y en tallos de plantas sanas de arveja, que se encontraban en focos con amarillamiento, que se sembraron y se multiplicaron en agar Cetrimide, obteniendo las cepas PPC, PPO y PPL, después de haber realizado pruebas morfológicas y bioquímicas. Para evaluar el antagonismo, las pruebas duales se produjeron en medio Agar Nutriente, donde la cepa PPC presentó mayor control del crecimiento de $F$. oxysporum bajo condiciones in vitro. En las pruebas de invernadero, la incidencia de la enfermedad contrastó de un 90,31 a 6,55\% con la bacteria, con respecto al testigo, mostrando la eficiencia antagónica de la cepa PPC de P. fluorescens en el control de F. oxysporum, bajo condiciones controladas.

Palabras clave: Control Biológico, Rizobacteria, incidencia, amarillamiento.

\section{SUMMARY}

The yellowing pea caused by Fusarium oxysporum is the most problem in the crop and its damage to bring economic losses. This research was carried out in the laboratory and greenhouse of the University of Nariño, located at 2486 masl to an average temperature of $13^{\circ} \mathrm{C}$., in order to evaluate the antagonism of $P$. fluorescent facing $F$. oxysporum on pea Pisum sativum $\mathrm{L}$. The isolation of $F$. oxysporum affected tissue was made from roots and stems of pea plants, which were multiplied and purified on PDA, strain selection was based on the prevalence in all zones and the speed in their growth, obtaining the strain FTR. The isolation of $P$. fluorescent was made from roots and stems of healthy pea plants that were in focus with yellowing, which were purified and multiplied in Selective Cetrimide Agar, obtaining strains PPC, PPO and PPL; after biochemical tests. The tests were made in dual in medium Nutrient Agar, in which the strain showed higher PPC antagonism to control the growth of $F$. oxysporum under In vitro conditions in the laboratory. In greenhouse tests the incidence rose from $90.31 \%$ to $6.55 \%$ with the bacteria compared with the control, showing the efficiency of the antagonistic strain $P$. fluorescens PPC in the control of $F$. oxysporum under controlled conditions.

Key words: Biological Control, Rhizobacteria, incidence, yellowing. 


\section{INTRODUCCIÓN}

En Colombia, la arveja (Pisum sativum L.) es cultivada en minifundios, localizados en zonas de ladera, en alturas comprendidas entre los 2.000 y $3.000 \mathrm{msnm}$, con temperaturas promedios de 12 a $17 \circ \mathrm{C}$ (Tamayo, 2002). Existen variedades. como la Piquinegra, la Parda, la Pajarito, la Guatecana y Bogotana (CCI, 2000); sin embargo, el material Santa Isabel ocupa casi la totalidad del área sembrada, ya que satisface los requerimientos del mercado. La homogeneidad de la variedad representa una desventaja desde el punto de vista fitosanitario, haciendo que el manejo de enfermedades producidas por patógenos sea cada vez más costosa y difícil (FENALCE, 2002).

El amarillamiento causado por Fusarium oxysporum f. sp. pisi Schtdl en arveja, es una de las enfermedades prevalentes y dañinas, en cultivos intensivos. Esta enfermedad puede ocasionar pérdidas que varían del 30 al 50\%, dependiendo de la incidencia, especialmente, en variedades susceptibles y bajo condiciones climáticas favorables para el desarrollo del patógeno. Los síntomas de la enfermedad inician con una clorosis, seguida por el achaparramiento de las plantas, que luego se marchitan y, finalmente, mueren (Tamayo, 2002; Buitrago et al. 2006; FENALCE, 2007). En el departamento de Nariño al no encontrarse variedades resistentes al amarillamiento, la rotación de cultivos y los sistemas de prevención, aun cuando sean técnicas seguras, tienen un valor limitado y, el control químico, se convierte en uno de los métodos más utilizados, pero no suficiente, ya que el hongo se encuentra ampliamente distribuido y es persistente en los suelos; en tiempos de lluvia, la incidencia incrementa a escalas epidémicas, con pérdidas considerables para los agricultores (Sañudo et al. 2001).

Las bacterias del género Pseudomonas tienen un gran potencial de degradación de compuestos aromáticos y xenobióticos, presentando la capacidad de colonizar el sistema radicular de plantas, formar biopelículas y ser manejable desde el punto de vista genético (Matthijs et al. 2007). Pseudomonas fluorescens Migula es un grupo de bacterias habitantes del suelo, estas son predominantemente numerosas en la microflora de la rizosfera de muchas plantas, siendo las primeras en colonizar las raíces jóvenes. Mucho de estos organismos suprimen enfermedades en las plantas, protegiendo las raíces y las semillas de la infección de los patógenos presentes en el suelo (Weller, 1988).

Según Lim et al. 1991; Loper \& Buyer, 1991; Mukerji, 2004 y Matthijs et al. 2007, $P$.fluorescens, se ha registrado como antagonista de $F$. oxysporum en varias especies vegetales. En la actualidad, se están estudiando nuevas formas de manejo para el control de plagas y de enfermedades, puesto que los mercados internacionales tienen estrictas medidas para el ingreso de productos agrícolas con trazas de productos químicos, como se establece en el Acuerdo de Medidas Sanitarias y Fitosanitarias (MSF) (OMC, 2008), por lo cual, se crea la necesidad de adoptar nuevas alternativas de manejo.

Con base en lo anteriormente expuesto, se planteó el presente trabajo de investigación, con el objetivo de aislar, desde la rizosfera de plantas de arveja, cepas de P. fluorescens, para evaluar antagonismo contra $F$. oxysporum f. sp. pisi bajo condiciones de laboratorio e invernadero, sobre las variedades de arveja ICA-CORPOICA Sindamanoy, Obonuco Andina, Obonuco, San Isidro y Santa Isabel.

\section{MATERIALES Y MÉTODOS}

El presente trabajo, se realizó en el laboratorio de microbiología e invernadero de la Universidad de Nariño, en la sede de Torobajo (Pasto, Nariño), situado a una altura de $2.486 \mathrm{msnm}$ y a una temperatura promedio de $13^{\circ} \mathrm{C}$.

Para el aislamiento de las $P$. fluorescens, así como de $F$. oxysporum, las muestras se recolectaron en lotes de arveja ubicados en los municipios de Potosí, de Ipiales, de Pupiales, de Yacuanquer, de Imués, de Tangua y los corregimientos de Mapachico, de Catambuco y de La Laguna, en el municipio de Pasto. Para el aislamiento y la purificación de F. oxysporum, se tomaron tejidos afectados de raíces y de tallos, se cortaron trozos de $5 \mathrm{~mm}$ de lado, los cuales, se desinfectaron durante dos minutos en hipoclorito de sodio al $0,5 \%$; luego, se hizo un enjuague durante un minuto en agua destilada. Posteriormente, se colocaron los cortes sobre papel filtro esterilizado, hasta que no se observó humedad. Para la siembra, se colocaron cuatro trozos en cajas de Petri, con medio de cultivo papa dextrosa agar (PDA), formando un cuadrado; luego, se sometieron a incubación a 25 y $28^{\circ} \mathrm{C}$, observando diariamente la aparición de colonias (Ávila de Moreno, (2003). Para la identificación del hongo, se montaron placas con las estructuras del hongo agregando lactofenol, más azul de algodón, para su tinción. Se observaron al microscopio electrónico, tomando como criterios taxonómicos los propuestos por Alexopoulus et al. (1996), Booth (1977) y Barnett (1960).

La cepa de $F$. oxysporum, se seleccionó evaluando el crecimiento de las colonias durante quince días, en cajas Petri con PDA; las mediciones, se hicieron en milímetros día y se realizaron con un calibrador pie de rey, seleccionando, únicamente, la cepa con una mayor velocidad de crecimiento y prevalencia en las zonas en estudio, de acuerdo a su coloración, Alexopoulus et al. (1996); Sañudo et al. (2003).

Para el aislamiento de la bacteria antagonista, el material vegetal se seleccionó de plantas sanas, en donde se presentaban focos de plantas con los síntomas de amarillamiento, marchitamiento y muerte, en este caso, de las raíces de plantas; se cortaron en trozos de $5 \mathrm{~mm}$ de 
longitud y se depositó en Beakers de vidrio, con 300ml de agua estéril desionizada; después de agitar manualmente durante 15 minutos y de esta solución, se realizaron las siembras por dilución sobre placas de medio de Agar Cetrimide (MERCK 5284), que es selectivo para $P$. fluorescens. Para la purificación, se tomaron colonias individuales, que fueron llevadas a cajas Petri con Agar Cetrimide y Agar King B, para pruebas de fluorescencia (Pérez E Leguizamón, 1998).

La selección de las cepas de la bacteria, se procedió únicamente con las colonias que dieron positivo a pruebas de Fluorescencia, negativas a tinción de Gram y positivas para oxidasa (Matthijs et al. 2007).

El crecimiento dual, se efectuó en cajas Petri con Agar Nutriente, ya que en PDA el desarrollo de la bacteria es mínimo; se sembraron discos de $10 \mathrm{~mm}$ de diámetro de la colonia pura de $F$. oxysporum, extraída previamente con sacabocados en los extremos de la caja Petri con PDA; la colonia pura de $P$. fluorescens fue extraída previamente de cajas con medio de cultivo Agar Cetrimide y sembrada tres días después en la misma caja Petri, a una distancia de 70mm de la colonia de $F$. oxysporum, usando, de igual forma, un disco de $10 \mathrm{~mm}$ de diámetro de cada cepa (Sañudo et al. 2003)

La incubación, se efectuó a temperatura ambiente con un monitoreo diario durante 45 días; las mediciones del crecimiento del hongo, la bacteria y el halo de inhibición, se hicieron en $\mathrm{mm}$ y fueron realizadas con un calibrador pie de rey, siendo suspendidas hasta que el halo de inhibición de la bacteria logró crecer hasta el extremo opuesto del crecimiento micelial del hongo (Márquez et al. 2002).

Se elaboró un Diseño Irrestrictamente al Azar con tres tratamientos (Cepa PPC, PPO y PPL de P. fluorescens) y cinco repeticiones; los tratamientos correspondieron a las tres cepas bacterianas. Los resultados obtenidos, se analizaron mediante un Análisis de Varianza y una Prueba de Significancia de Tukey, en el programa estadístico Statgraphics Plus versión 5.1.

Las pruebas de invernadero, se efectuaron con cuatro variedades de arveja ICA CORPOICA Sindamanoy (ICS), Obonuco Andina (OA), Obonuco San Isidro (OSI), Santa Isabel (SI), empleando un Diseño irrestrictamente al Azar, con arreglo factorial $4 \times 4$, que correspondió a 16 tratamientos y cinco repeticiones; la unidad experimental estuvo compuesta por cinco plantas sembradas individuamente en bolsas de $1 \mathrm{~kg}$, con suelo previamente esterilizado.

La inoculación con Pseudomonas consistió en semillas de arveja, previamente inoculadas durante 24 horas, en una solución de 50c.c. de agua esterilizada y $P$.fluorescens, a una concentración de $9 \times 10^{6} \mathrm{ufc} / \mathrm{ml}$, de acuerdo a la escala de McFarland's (Király et al. 1974); las semillas fueron inoculadas un día antes de la siembra (Pérez et al. 2000).

La inoculación con Fusarium consistió en el empleo de semillas de arveja sin contaminación bacterial, inoculándose el sustrato siete días previos a la siembra con F. oxysporum, con una solución de 50c.c. de agua esterilizada y $F$. oxysporum, a una concentración de $1 \times 10^{6}$ conidias por mililitro, obtenidas en la cámara de Neubauer, siendo aplicada esta solución por bolsa.

La inoculación con $F$. oxysporum $+P$. fluorescens consistió en sustrato inoculado siete días previos a la siembra con $F$. oxysporum, en una solución de 50c.c. de agua esterilizada a una concentración de 1 x $10^{6}$ conidias por mililitro, obtenidas en la cámara de Neubauer, siendo aplicada esta solución por bolsa, y semillas de arveja, previamente inoculadas 24 horas antes de la siembra, en una solución 50c.c. de agua esterilizada y $P$. fluorescens, con una concentración de 9 × $10^{6}$ ufc/ $\mathrm{ml}$, obtenidas en la cámara de Neubauer, las semillas fueron inoculadas un día antes de la siembra (Pérez et al. 2000).

Para el caso del testigo, no se realizó ningún tipo de inoculación en las semillas de arveja y el sustrato.

Las variables evaluadas fueron el porcentaje de emergencia, la cual, se evaluó durante los primeros siete días posteriores a la siembra, con la siguiente fórmula: Porcentaje de emergencia $=$ (Número de plántulas emergidas / Número de semillas sembradas) x 100 y días a emergencia durante los primeros siete días posteriores a la siembra, contando el número de días que se tardó en emerger cada semilla en la bolsa. La incidencia de la enfermedad, se evaluó por la sintomatología de las plantas descrita por Tamayo (2002); esta evaluación se realizó durante sesenta días.

Los resultados obtenidos, se sometieron a un Análisis de Varianza y una Prueba de Significancia de Tukey al 0.05 en el programa estadístico Infostat Profesional 1.1. Además, para el análisis de varianza del porcentaje de emergencia y el de incidencia, se efectuó una trasformación con la fórmula: Arcosen $\sqrt{ } \mathrm{X}$.

\section{RESULTADOS Y DISCUSIÓN}

En el muestreo realizado en las distintas zonas en estudio del Departamento de Nariño con problemas de amarillamiento en arveja, se obtuvieron tres tipos de cepas de F. oxysporum (Tabla 1), que se caracterizaron por presentar macroconidias curvadas y pluriseptadas, con una célula apical más o menos puntiaguda (Figura 1E y 1F); también se halló microconidias unicelulares, similares en ancho a los macroconidias, con una base redondeada o truncada; el micelio encontrado fue denso y algodonoso, correspondientes al género Fusarium (Alexopoulos et al. 1996; Booth,1977; Barnett, 1960). 
Tabla 1. Distribución y característica morfológica de las cepas de Fusarium oxysporum.

\begin{tabular}{|c|c|c|c|c|}
\hline \multicolumn{1}{|r|}{ Color } & Rojo & Rosado & Anaranjado \\
\hline Zona & Catambuco & $\mathrm{X}$ & & $\mathrm{X}$ \\
\hline Zona centro & Mapachico & $\mathrm{X}$ & $\mathrm{X}$ & \\
\hline & La laguna & $\mathrm{X}$ & $\mathrm{X}$ & $\mathrm{X}$ \\
\hline Zona cerealista & Yacuanquer & $\mathrm{X}$ & $\mathrm{X}$ & $\mathrm{X}$ \\
\hline & Imues & $\mathrm{X}$ & $\mathrm{X}$ & \\
\hline & Tangua & $\mathrm{X}$ & $\mathrm{X}$ \\
\hline
\end{tabular}

A

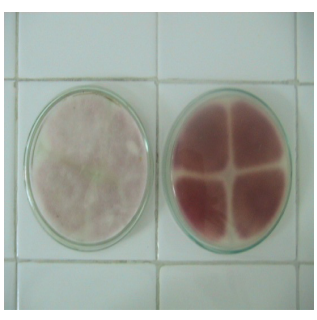

E

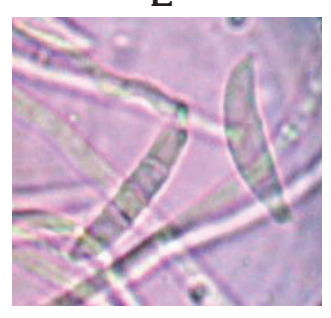

B

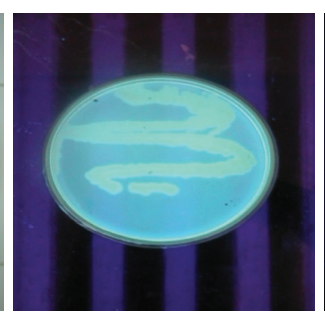

$\mathrm{F}$

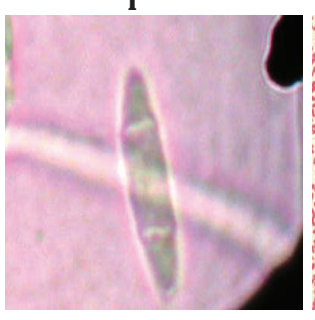

C

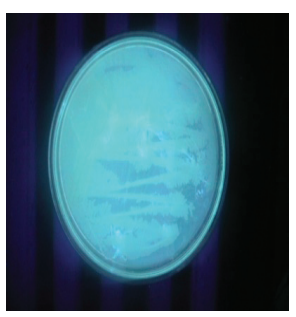

G

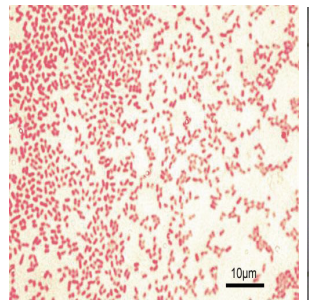

D

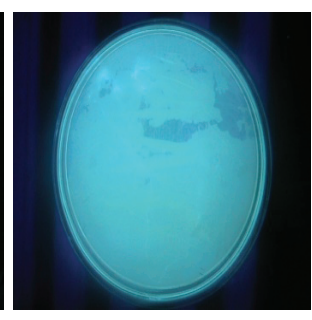

$\mathrm{H}$

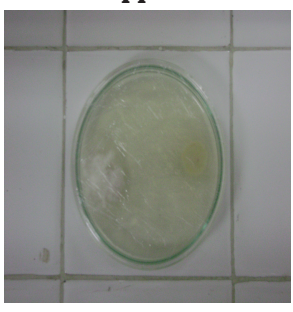

Figura 1. Aislamiento e identificación de cepas de F. oxysporum y $P$. fluorescens. A. Cepa de F. oxysporum FTR de coloración rojiza. B. Cepa de P. fluorescens PPC. C. Cepa de P. fluorescens PPO. D. Cepa de P. fluorescens PPL. E. Conidioforo. F. Acercamiento macroconidia septada en 3. G. P. fluorescens al microscopio (tinción de Gram). H. Antagonismo.

En la zona Centro, se percibieron cinco cepas; en la Cerealista, siete y en la zona Sur, cinco, siendo la más abundante la de coloración rojiza. Según Seifert (2001), las colonias de los distintos F. oxysporum que crecen moderada a profusamente, tienen diversos colores, especialmente, en el reverso de la colonia, excepto pardo oscuro o negro.
La selección de la cepa de $F$. oxysporum, se basó en la morfología o el crecimiento de las cepas, encontrándose que la cepa FTR, correspondiente al municipio de Tangua de color rojo (Figura 1A), tuvo un promedio de crecimiento $0,2 \mathrm{~mm} /$ día de radio más que las otras cepas aisladas; esta, al igual que las otras de la misma coloracion, localizadas en todas las zonas en estudio, obtuvieron un promedio de crecimiento similar, por lo que fue indiferente la utilizacion de una cepa específica en particular de la misma coloracion. 
Terminado el procedimiento de aislamiento y de purificación de la bacteria antagonista, se determinó que las cepas fueron Gram negativas (Figura 1G); al microscopio, se observaron bacilos cortos; además, fueron positivas para las pruebas de fluorescencia bajo luz ultra violeta y de oxidasa, según los resultados obtenidos en las pruebas correspondientes, por lo tanto, se afirma que corresponden a P. fluorescens, comparado con los parámetros establecidos por Matthijs et al. (2007) y Booth (1977).

Se seleccionaron tres cepas potenciales de $P$. fluorescens, que fueron las encontradas en el municipio de Pasto, corregimiento de Catambuco: PPC (Figura 1B); en el municipio de Potosí: PPO (Figura 1C) y, una última, en el municipio de Pasto, corregimiento de La Laguna: PPL (Figura 1D).

La longitud del halo de inhibición de $P$. fluorescens frente a $F$. oxysporum después del punto de encuentro, se obtuvo diferencias estadísticas significativas, como se registran en el análisis de varianza (Tabla 2).

Al comparar los promedios de longitud de invasión en mm y utilizando prueba de Tukey, como se observa en la tabla 2,

Tabla 2. Análisis de varianza y comparación de los promedios de longitud del halo de inhibición in vitro dada en mm, de las tres cepas de $P$. fluorescens, utilizando prueba de Tukey $95 \%$.

\begin{tabular}{|c|c|c|c|c|c|}
\hline Fv & Gl & Sc & Cm & Fc & Ft \\
\hline Tratamientos & 2 & 414,12 & 207,06 & $8,79 *$ & 0,0045 \\
\hline Error & 12 & 282,60 & 23,55 & & \\
\hline Total & 14 & 696,72 & & & \\
\hline
\end{tabular}

* Diferencias significativas $(\mathrm{p} \leq 0,05)$.

\begin{tabular}{|c|c|c|c|}
\hline Tratamiento & Cepa bacteriana & Medida & Agrupación tukey \\
\hline 1 & Ppc & 11,38 & A \\
2 & Ppo & 0,45 & B \\
3 & Ppl & 0,03 & B \\
\hline
\end{tabular}

Tratamientos con letras distintas indican diferencias significativas.

se determinó que la longitud promedio del halo de inhibición fue de $11,38 \mathrm{~mm}$, en presencia de la cepa bacteriana PPC, presentó diferencias significativas en relación a los tratamientos anteriores, a diferencia de la longitud promedio reflejada en presencia de las cepas bacterianas PPO y PPL, con $0,4 \mathrm{~mm}$ y $0,03 \mathrm{~mm}$, no presentaron diferencias estadísticas significativas.

En los días a emergencia, se determinó que las variedades ICA CORPOICA Sindamanoy, Obonuco Andina, Obonuco San Isidro y Santa Isabel, con el sistema de inoculación con P. fluorescens mostraron, en promedio, el menor número de días, con 4,7 días; además, el sistema de inoculación con Fusarium+Pseudomonas, con 5,1 días, reveló los menores días a emergencia respecto al testigo, con 5,65 días, debido a la previa inoculación con $P$. fluorescens, que actuó como agente promotor de desarrollo y de crecimiento, concordando con lo encontrado por García (2007).
Las bacterias promotoras del crecimiento vegetal (PGPR) como las $P$. fluorescens, se destacan por sus efectos positivos, tanto para las plantas como para los ecosistemas; este efecto se manifiesta a través de diferentes mecanismos de acción. Existe una cierta proporción, posiblemente, se deban a efectos antimicrobiales directos o indirectos, ya que muchos estudios arrojaron que las $P$. fluorescens inhiben el crecimiento y deterioran algunos microorganismos patógenos, entre ellos F. oxysporum (Cook, 1993).

Los días a emergencia con el sistema de inoculación con Fusarium con un promedio de 6,35 días fue el que más retraso tuvo con respecto al testigo y a los sistemas de inoculación de $P$. fluorescens y de Fusarium $+P$. fluorescens, debido a la presión ejercida por el patógeno, que impide el desarrollo en el proceso de germinación y de emergencia de la plántula (Agrios, 2002). 
El análisis de varianza (Tabla 3) del porcentaje de emergencia mostró diferencias estadísticas altamente significativas entre las inoculaciones, al igual que entre las variedades de arveja. En la interacción, se registraron diferencias estadísticas significativas, indicando que las inoculaciones y las variedades no actúan independientemente sobre el porcentaje de emergencia.
Al comparar los promedios de los porcentajes de emergencia y utilizando la prueba de Tukey (Tabla 3), se determinó que los más altos porcentajes los presentaron las variedades San Isidro, Santa Isabel, Andina y Sindamanoy, con el sistema de inoculación de Pseudomonas, con 99,50, 99 y 98,5\% de emergencia, presentando promedios estadísticos similares entre sí, distinto estadísticamente al sistema de inoculación de las variedades San Isidro, Andina, Santa Isabel y Sindamanoy,

Tabla 3. Análisis de varianza y comparación de los promedios del porcentaje de emergencia, utilizando prueba de Tukey 95\%.

\begin{tabular}{|c|c|c|c|c|c|}
\hline FV & GL & SC & CM & FC & p-valor \\
\hline & 3 & 1,4307 & 0,4769 & $289,61^{* *}$ & $<0,0001$ \\
\hline VARIEDADES & 3 & 0,0806 & 0,0269 & $16,31^{* *}$ & $<0,0001$ \\
\hline INOC. X VAR. & 9 & 0,0413 & 0,0046 & $2,79 *$ & 0,0081 \\
\hline ERROR & 64 & 0,1054 & 0,0016 & & \\
\hline TOTAL & 79 & 1,6579 & & & \\
\hline
\end{tabular}

** Diferencias altamente significativas $(p \leq 0,0001)$; *: Diferencias significativas ( $\leq \leq 0,05)$.

\begin{tabular}{|c|c|c|c|}
\hline INOCULACIÓNES & VARIEDAD & MEDIA & AGRUPACIÓN TUKEY \\
\hline Pseudomonas & SAN ISIDRO & 99,50 & $\mathrm{~A}$ \\
\hline Pseudomonas & SANTA ISABEL & 99,00 & $\mathrm{~A}$ \\
\hline Pseudomonas & ANDINA & 98,50 & $\mathrm{AB}$ \\
\hline Pseudomonas & SINDAMANOY & 98,50 & $\mathrm{AB}$ \\
\hline Fusarum+Pseudomonas & SAN ISIDRO & 97,50 & $\mathrm{BC}$ \\
\hline Fusarum+Pseudomonas & ANDINA & 97,00 & $\mathrm{BC}$ \\
\hline Fusarum+Pseudomonas & SANTA ISABEL & 96,50 & $\mathrm{CD}$ \\
\hline Fusarum+Pseudomonas & SINDAMANOY & 96,00 & $\mathrm{CD}$ \\
\hline Testigo & ANDINA & 94,00 & $\mathrm{DE}$ \\
\hline Testigo & SAN ISIDRO & 94,00 & $\mathrm{DE}$ \\
\hline Testigo & SINDAMANOY & 93,50 & $\mathrm{DE}$ \\
\hline Testigo & SANTA ISABEL & 93,50 & $\mathrm{DE}$ \\
\hline Fusarium & ANDINA & 88,50 & $\mathrm{E}$ \\
\hline Fusarium & SAN ISIDRO & 88,00 & $\mathrm{E}$ \\
\hline Fusarium & SANTA ISABEL & 85,00 & $\mathrm{~F}$ \\
\hline Fusarium & SINDAMANOY & 84,50 & $\mathrm{~F}$ \\
\hline
\end{tabular}

Tratamientos con letras distintas indican diferencias significativas. 
con el sistema de inoculación Fusarium +Pseudomonas; al igual que de las variedades Andina, San Isidro, Santa Isabel y Sindamanoy, con el sistema de inoculación Fusarium y de los testigos, con respecto a los testigos de estas variedades.

Las variedades San Isidro, Andina, Santa Isabel y Sindamanoy, con el sistema de inoculación Fusarium+Pseudomonas, con 97,5, 97, 96,5 y 96\%, respectivamente, presentaron promedios similares entre sí y distintos a las variedades Andina, San Isidro, Santa Isabel y Sindamanoy, con el sistema de inoculación Fusarium, con 88,5, 88, 85 y 84,5\% de emergencia que presentaron promedios similares entre sí y diferentes al nivel de significancia ( $p \leq 0,05$ ), con respecto a los Testigos Andina y San Isidro con $94 \%$ y de Sindamanoy y Santa Isabel, con 93,5\% de emergencia.

Las variedades Andina, San Isidro, Santa Isabel y Sindamanoy con los sistemas de inoculación Pseudomonas y Fusarium +Pseudomonas tuvieron el más alto porcentaje de emergencia con respecto al testigo y a las inoculaciones con Fusarium, debido a que las $P$. fluorescens, además de proteger las plantas al ataque de patógenos, también son rizobacterias promotoras de crecimiento, dando como resultado una reducción en la severidad de las distintas enfermedades fungosas que se puedan presentar y un aumento en el desarrollo de las plantas (Alström, 1991).

Las $P$. fluorescens poseen la propiedad de producir sustancias, cuyas principales ventajas son las de estimular la germinación de las semillas, acelerar el crecimiento de las plantas, especialmente en sus primeros estadios, inducir la iniciación radicular e incrementar la formación de raíces y pelos radiculares (Cornelis, 2008).

En cuanto al porcentaje de incidencia de la enfermedad, se hallaron diferencias estadísticas altamente significativas entre los tratamientos; entre las variedades de arveja, se encontraron diferencias estadísticas significativas.

Tabla 4. Análisis de varianza y comparación de los promedios del porcentaje de incidencia de la enfermedad utilizando prueba de Tukey $95 \%$.

\begin{tabular}{|c|c|c|c|c|c|}
\hline FV & GL & SC & CM & FC & p-valor \\
\hline INOCULACIONES & 3 & 50,06 & 16,69 & $1711,90^{* *}$ & $<0,0001$ \\
\hline VARIEDADES & 3 & 0,17 & 0,06 & $5,65^{*}$ & 0,0017 \\
\hline INOC. $*$ VAR. & 9 & 0,56 & 0,06 & $6,33 * *$ & $<0,0001$ \\
\hline ERROR & 64 & 0,62 & 0,01 & & \\
\hline TOTAL & 79 & 51,40 & & & \\
\hline
\end{tabular}

** Diferencias Altamente significativas ( $\leq 0,0001)$; *: Diferencias Significativas ( $\leq \leq 0,05)$.

\begin{tabular}{|c|c|c|c|}
\hline INOCULACIONES & VARIEDAD & MEDIA & AGRUPACIÓN TUKEY \\
\hline Fusarium & SAN ISIDRO & 92,64 & $\mathrm{~A}$ \\
\hline Fusarium & ANDINA & 90,98 & $\mathrm{~A}$ \\
\hline Fusarium & SANTA ISABEL & 88,86 & $\mathrm{~A}$ \\
\hline Fusarium & SINDAMANOY & 88,76 & $\mathrm{~A}$ \\
\hline Fusarum+Pseudomonas & SINDAMANOY & 8,98 & $\mathrm{~B}$ \\
\hline Fusarum+Pseudomonas & SANTA ISABEL & 8,98 & $\mathrm{~B}$ \\
\hline Fusarum+Pseudomonas & SAN ISIDRO & 4,16 & $\mathrm{C}$ \\
\hline Fusarum+Pseudomonas & ANDINA & 4,08 & $\mathrm{C}$ \\
\hline Testigo & SINDAMANOY & 0,54 & $\mathrm{D}$ \\
\hline Testigo & ANDINA & 0,52 & $\mathrm{D}$ \\
\hline Testigo & SAN ISIDRO & 0,00 & $\mathrm{D}$ \\
\hline Pseudomonas & SAN ISIDRO & 0,00 & $\mathrm{D}$ \\
\hline Pseudomonas & SANTA ISABEL & 0,00 & $\mathrm{D}$ \\
\hline Pseudomonas & SINDAMANOY & 0,00 & $\mathrm{D}$ \\
\hline Pseudomonas & ANDINA & 0,00 & $\mathrm{D}$ \\
\hline Testigo & SANTA ISABEL & 0,00 & $\mathrm{D}$ \\
\hline
\end{tabular}

Tratamientos con letras distintas indican diferencias significativas. 
En la interacción, se percibieron diferencias estadísticas altamente significativas, indicando que las inoculaciones y las variedades no actúan independientemente sobre el porcentaje de incidencia, como se registra en el análisis de varianza (Tabla 4).

Al comparar los promedios del porcentaje de incidencia y utilizando la prueba de Tukey, como se observa en la tabla 4 , se determinó que el más alto porcentaje de incidencia se presentó en las variedades San Isidro, Andina, Santa Isabel y Sindamanoy, con el sistema de inoculación con Fusarium $92,64,90,98,88,86$ y $88,76 \%$ de incidencia, presentando promedios estadísticos similares entre sí.

Distinto, estadísticamente de las variedades Sindamanoy, Santa Isabel, San Isidro y Andina, con un sistema de inoculación con Fusarium+Pseudomonas; al igual que San Isidro, Santa Isabel, Sindamanoy y Andina, con un sistema de inoculación con Pseudomonas y de los testigos Sindamanoy, Andina, San Isidro y Santa Isabel.

Las variedades San Isidro, Andina, Sindamanoy y Santa Isabel, con un sistema de inoculación con Fusarium+Pseudomonas, con 4,16, 4,08 y 8,98\% de incidencia que presentaron promedios similares entre sí y diferentes al nivel de significancia ( $p \leq 0,05)$, con respecto a los Testigos con las variedades San Isidro y Santa Isabel, con $0 \%$ y de las variedades Sindamanoy y Andina, con 0,54 y $0,52 \%$ de incidencia, al igual que con el sistema de inoculación con Pseudomonas, con las variedades San Isidro, Santa Isabel, Sindamanoy y Andina, con $0 \%$ de incidencia.

En las variedades ICA CORPOICA Sindamanoy, Obonuco Andina, Obonuco San Isidro y Santa Isabel, frente a las inoculaciones con $F$. oxysporum, con un promedio de $90,31 \%$ de incidencia, se presentó un alto porcentaje de incidencia de la enfermedad con respecto a los testigos, de ahí que se confirma lo reportado por Campuzano et al. (1992; 2001), Checa (1995) y Sañudo et al. (1993), quienes afirman que estos genotipos son altamente susceptibles a la enfermedad.

Las variedades de arveja inoculadas con F. oxysporum presentaron lesiones localizadas, principalmente, en la base del tallo y en la parte superior de la raíz; las lesiones fueron alargadas, pardo rojizas, ligeramente hundidas (Buitrago et al. 2006; Sañudo et al. 2001); estas lesiones se pueden extender a las raíces secundarias y la parte inferior del sistema radical.

La lesión del tallo es primariamente cortical, pero en algunos casos, se puede extender una decoloración rojiza del sistema vascular, hasta una corta distancia sobre la lesión cortical. Este último síntoma consigue incluir a confusión con el marchitamiento, pero, en general, el limitado alcance de la decoloración vascular es suficiente para distinguir el ataque del patógeno. En las partes epigeas, los síntomas consisten en un precario desarrollo; en los casos extremos, la planta se marchita y muere (Martínez et al. 2004).

Las inoculaciones con P. fluorescens disminuyen la incidencia de la enfermedad, lo cual, se debe a la baja presión ejercida por el patógeno (Mukerji, 2004) y a la producción de uno o más metabolitos, como el 2- 4 diacetyl-phloroglucinol, incluyendo sideróforos, antibióticos, cianuro y enzimas líticas $\mathrm{e}$, incluso, las $P$. fluorescens pueden inducir resistencia para ciertos patógenos en las plantas; esta inducción activa los mecanismos de defensa de la plantas, ya sea como barreras físicas o químicas, dependiendo del hospedante y de la efectividad de la colonización de las raíces por Pseudomonas. Se piensa que las pyoverdinas producidas por $P$. fluorescens facilitan el control biológico, apropiándose del hierro que está presente en la rizosfera, ayudando a la limitación severa de hierro en el ambiente en las raíces de la planta, por consiguiente, se observa el descenso de otros organismos y por último, la supresión de distintos microorganismos (Buyer E Leong, 1986).

El papel de las enzimas micolíticas, como la quitina, producidas por las $P$. fluorescens, en la supresión de patógenos es de gran importancia en su control de patógenos. Si las plantas no contienen quitina en las paredes de las células, se puede hacer el uso de protectores de plantas con quitina, que también lo tienen los hongos patógenos. Microscopias electrónicas han revelado la interacción de $F$. oxysporum y $P$. fluorescens, y la degradación del micelio de $F$. oxysporum, puesto que las enzimas líticas producidas de manera extracelular inhiben el micelio y el crecimiento del conidióforo, en vez de la germinación de la espora. La micólisis, por lo tanto, se define como la pérdida del protoplasma en la estructura del hongo y la disolución enzimática de la célula (Lim et al. 1991).

P. fluoresens produce antibiótico, siendo éste altamente inhibitorio para $F$. oxysporum; se mostraron que los mecanismos de supresión en contra de los hongos puede involucrar enzimas líticas en vez de antibióticos. P. stutzeri YPL-1 produce, de manera extracelular, quitinasa y laminaríansa, cuando crece el micelio de $F$. oxysporum fsp. solani, produciéndose polímeros de quitina y de laminarína (Lim et al. 1991).

Los antibióticos producidos por algunas $P$. fluorescens son de gran importancia, destacándolos en la supresión de enfermedades en las plantas (Mukerji, 2004). La resistencia sistémica inducida por $P$. fluorescens inducen a un cambio sostenido en la planta, incrementando la tolerancia a la infección de patógenos, este fenómeno promueve la resistencia inducida, activando las defensas de las plantas (Uknes et al. 1993). 
Las cepas de $P$. fluorencens fueron eficientes para el control de $F$. oxysporum en condiciones controladas, pero existe la necesidad de ser probada en condiciones de campo, para evaluar su eficiencia en el control del patógeno. Igualmente, se detectó que la cepa de $P$. fluorencens PPC disminuyó la incidencia de la enfermedad de un $90,31 \%$ a $6,55 \%$ con relación al testigo en presencia de la bacteria, mostrando gran eficiencia en el control de $F$. oxysporum, en condiciones de invernadero.

Agradecimientos. Los autores agradecen la realización de este estudio a la Universidad de Nariño, Facultad de Ciencias Agrícolas, Programa de Ingeniería Agronómica, Grupo de Investigación de Sanidad Vegetal. Conflictos de intereses: El manuscrito fue preparado y revisado con la participación de todos los autores, quienes declaramos que no existe ningún conflicto de intereses que ponga en riesgo la validez de los resultados presentados. Financiación: Este estudio fue financiado por la Universidad de Nariño.

\section{BIBLIOGRAFÍA}

1. AGRIOS, G. 2002. Fitopatología. Editorial Limusa, México.835p.

2. ÁVILA DE MORENO, C. 2003. Manual de laboratorio de fitopatología. Tunja: UPTC. p.17-19.

3. ALEXOPOULOS, C.J.; MIMS, C.W.; BLACKWELL, M. 1996. Introductory mycology. 4a ed. Editorial Wile E Sons, N.Y. 578p.

4. ALSTRÖM, S. 1991. Induction of disease resistance in common bean susceptible to halo blight bacterial pathogen after seed bacterization with rhizosphere pseudomonads. J. Gral Appl. Environm. Microbiol. 37:495-501.

5. BARNETT, H.L. 1960. Illustrated genera of imperfect fungi. Burgess Publishing Co., Minneapollis. 215p.

6. BOOTH, C. 1977. The Genus Fusarium. Editorial CMI. Kew, Surrey. p.19-31.

7. BUITRAGO E., J.Y.; DUARTE P., C.J.; SARMIENTO, A. 2006. El cultivo de la arveja en Colombia. Federación Nacional de Cultivadores de Cereales y Leguminosas -FENALCE- y Fondo Nacional Cerealista. Ed. Produmedios. Bogotá. Colombia. 83p.

8. BUYER, J.S.; LEONG J. 1986. Iron transport-mediated antagonism between plant growth-promoting and plant deleterious Pseudomonas strains. J. Biol. Chem. 261:791-794.

9. CHECA CORAL, O. 1995. Sindamanoy: variedad mejorada de arveja para clima frío. CORPOICA. 8p.

10. CAMPUZANO D., L.F.; YÉPEZ CHAMORRO, B.; BENAVIDES PAZMIÑO, J.; BOLAÑOS, M.A.; ARCILA GONZÁLEZ, B.; LÓPEZ DE B., C.M.; CEPEDA BRAVO, G. 1992. Obonuco Andina: nueva variedad mejorada de arveja para la zona de economía campesina del sur de Nariño. ICA. Bol. Div. No 9. 8p.

11. CAMPUZANO D., L.F.; YÉPEZ CHAMORRO, B.; BENAVIDES PAZMIÑO, J.; BOLAÑOS, M.A.; ARCILA GONZÁLEZ, B.; LÓPEZ DE B., C.M. 2001. Obonuco San Isidro: nueva variedad mejorada de arveja para la zona de reconversión de trigo en el departamento de Nariño. CORPOICA. Bol. Div. No 8. 8p.

12. COOK, R.J. 1993. Making greater use of introduced microorganisms for biological control of plant pathogens. Ann. Rev. Phytopath. 31:53-80.

13. CORNELIS, P. 2008. Pseudomonas: Genomics and Molecular Biology. Ed. Pierre Cornelis Vrije Universiteit Brussel, Belgium. p.14-25.

14. CORPORACIÓN COLOMBIA INTERNACIONAL CCI. 2000. Manual del exportador de frutas, hortalizas y tubérculos en Colombia. Disponible desde Internet en: http://www.cci.org.co/manual\%20Exportador/ desempeno_prod/princ_prod_mapas/princ_prod11. htm (con acceso 15/11/10).

15. FEDERACIÓN NACIONAL DE CULTIVADORES DE CEREALES Y LEGUMINOSAS FENALCE. 2007. Arveja. Disponible desde Internet en: http://www.fenalce.net/ pagina.php?p_a $=52$ (con acceso 04/11/10).

16. FEDERACIÓN NACIONAL DE CULTIVADORES DE CEREALES Y LEGUMINOSAS FENALCE. 2002. Conocimiento Técnico: Amarillamiento en arveja. Disponible desde Internet en: http://www. fenalceorg.c Cuotas.htm (con acceso 20/12/10).

17. GARCÍA, R. 2007. Efecto de la inoculación con rizobacterias promotoras del crecimiento de las plantas (PGPR) sobre el crecimiento de trigo y la eficiencia en el uso de fertilizante. Buenos Aires. Disponible desde Internet http://www.slideshare.net/soilteacher/garciaefecto-de-la-inoculacion-con-rizobacterias (con acceso 20/03/10). 
18. KIRÁLY, Z.; KLEMENT, Z.; SOLYMOSY, F.; VORAS, J. 1974. Methods in Plant Pathology. Elsevier Scientific Publishing Company. NewYork, USA. p.30-40.

19. LIM, H.S.; KIM, Y.S.; KIM, S.D. 1991. Pseudomonas stutzeri YLP-1 genetic transformation and antifungal mechanism against Fusarium solani, an agent of plant root rot. Appl. Environm. Microbiol. 57:510-516.

20. LOPER, J.E.; BUYER, J.S. 1991. Siderophores in micriobal interations on plants surfaces. Molecular Plant-Microbe Interactions. 4:5-13.

21. MÁRQUIEZ, M.; MARTÍNEZ, M.; FRANCO, M. 2002. Aislamiento de Trichoderma sp. y actinomycetes a partir de suelos de clavel (Dianthus caryophyllus) y evaluación de su capacidad antagónica in vitro sobre Fusarium oxysporum f. sp. dianthi. Agron. Colomb. 19(1-2):81-87.

22. MARTÍNEZ GARNICA, M.; HERNÁNDEZ DELGADO, S.; RAMÍRES PADILLA, J.; MAYEK PÉREZ, N. 2004. Diversidad genética y patogénica de Fusarium. Rev. Mexicana Fitopat. 22(3):321-927.

23. MATTHIJS, S.; TEHRANI, K.A.; LAUS, G.; JACKSON, R.W.; COOPER, R.M.; CORNELIS, P. 2007. Pseudomonas thioquinolobactin, a Pseudomonas siderophore with antifungal and anti-Pythium activity. Environ. Microbiol. 9(2):425-434.

24. MUKERJI, K.G. 2004. Fruits and vegetables. Dheli: Klower Academic Publisher. p.455-460.

25. ORGANIZACIÓN MUNDIAL DEL COMERCIO OMC. 2008. Medidas sanitarias y fitosanitarias. Disponible desde Internet en http://www.wto.org/spanish/tratop_s/ sps_s/sps_s.htm (con acceso 29/06/10).

26. PÉREZ, C.; DE LA FUENTE, L.; ARIAS, A.; ALTIERI, N. 2000. Uso de Pseudomonas fluorescens nativas para el control de enfermedades de implantación en Lotus corniculatus L. Agrociencia. 4(1):41-47.
27. PÉREZ N., J.C.; LEGUIZAMON C., J.E. 1998. Interacciones entre micorrizas nativas, Pseudomonas fluorescentes y Calcio en el manejo de Fusarium spp. en espárragos. Cenicafé (Colombia) 49(3):211-223.

28. SAÑUDO SOTELO, B.; CHECA CORAL, O.; ARTEAGA MENESES, G. 1993. Manejo agronómico de leguminosas en zonas cerealistas. Ed. Universidad de Nariño. Colombia: Pasto. p.49-60.

29. SAÑUDO SOTELO, B.; CHECA CORAL, O.; ARTEAGA MENESES, G. 2001. Perspectivas para el desarrollo agrícola de la zona triguera de Nariño. Ed. Universidad de Nariño. Colombia: Pasto. 214p.

30. SAÑUDO SOTELO, B.; ARTEAGA, M.; VALLEJO, W.; FIGUEROA, R.; BURBANO, E. 2003. Fundamentos de Micología agrícola. Ed. Universidad de Nariño. Colombia: Pasto. 201p.

31. SEIFERT, K.F. 2001. Fusarium and anamorph generic concepts. Agriculture and Agri-Food. En: Summerell, B.A.; Leslie, J.F.; Backhouse, D.; Bryden, W.L.; Burgess L.W. (Eds) Fusarium. APS Press St. Paul, Minnesota, Canada. p.70-79.

32. TAMAYO M., P.J. 2002. Enfermedades del cultivo de la arveja en Colombia: Guía de reconocimiento y control. Boletín técnico 14. Corpoica Regional 4. Colombia. 49p.

33. UKNES, S.; WINTER, A.M.; DELANEY, T.; VERNOOIJ, B.; MORSE, A.; FRIEDRICH, L.; NYE, G.; POTTER, S.; WARD, E.; RYALS, J. 1993. Biological induction of systemic acquired resistance in Arabidopsis. Mol. Plant-Microbe Interactions. 6:692-698.

34. WELLER, D.M. 1988. Biological control of soil - borne plant pathogens in the rhizosphere with bacteria. Ann. Rev. Phytopath. 26:379-469.

Recibido: Enero 20 de 2011

Aceptado: Octubre 10 de 2011 